\title{
Is Landscape a Driver of Short-term Wildfire Recurrence?
}

\author{
ANNA BARBATI*, PIERMARIA CORONA**, ENRICO D’AMATO*** \& \\ ROSARIA CARTISANO* \\ * Dipartimento per la Innovazione nei sistemi Biologici, Agroalimentari e Forestali (DIBAF), University of \\ Tuscia, Viterbo, Italy ${ }^{* * *}$ Forestry Research Centre (CRA-SEL), Arezzo, Italy ${ }^{* * *}$ Corpo Forestale dello Stato, \\ Rome, Italy
}

\begin{abstract}
Repeated burning in a short return period ( $<3-5$ years) may significantly contribute to land degradation in Mediterranean countries. We apply logistic regression analysis to model spatial relationships between reburning and site (topographic) and landscape-level factors (land use pattern); forest areas burned twice at least between 2006 and 2009 in the Italian peninsula are used as a case study. Few landscape factors prove to be correlated with the probability of fire recurrence, and the overall logistic regression model explains $24 \%$ of the variation in the fire recurrence. This fact is not surprising since human factors are known to be the biggest determinant of wildfire events in Mediterranean countries such as Italy. Nonetheless, findings from this exploratory study prove to be qualitatively helpful to identify at least landscape drivers, easily quantifiable and available on a national scale, significantly affecting short-term fire recurrence (i.e. slope roughness, exposure, distance from the nearest water body, pre-fire dominant forest type).
\end{abstract}

KEY WoRDS: Reburning, wildfire, landscape factors, logistic regression, Italy

\section{Introduction}

The so-called fuel-age paradigm states that previous fire history controls the spatial pattern of future fires with a time-dependent, non-random fuel-driven accumulation (Zedler \& Seiger, 2000). Yet, previous fires can determine conditions that favour cyclical patterns of fire occurrence at the same site, with a return period of even a very few years. There are various explanations for factors leading to this phenomenon. Some of the drivers most credited in the literature are: i) the creation of more connected and homogeneous vegetation patches (fuel continuity) after fire that helps to favour future fire spread (Lloret et al., 2002; Loepfe et al., 2010; van Leeuwen et al., 2010); ii) low fire resilience of forest communities which, when burned frequently, turns into more fire prone shrublands (Baeza \& Vallejo, 2008; Moreira et al., 2011); iii) fire-induced vegetation mortality which increases the amount and continuity of dead fuels (Collins et al., 2007). It is also recognised that variations in fire severity can enhance landscape heterogeneity creating patches with different age stages (Lloret et al., 2002; Pérez et al.,

Correspondence Address: Anna Barbati, Dipartimento per la Innovazione nei sistemi Biologici, Agroalimentari e Forestali (DIBAF), University of Tuscia, Via S. Camillo de Lellis snc, 01100 Viterbo, Italy. Email: barbati.sisfor@unitus.it 